\title{
Fabrication and Characterization of $\mathrm{LiMn}_{2} \mathrm{O}_{4}$ Thin Films for Flexible Thin Film Lithium-ion Batteries: Effect of thermal Annealing
}

\author{
Rongbin Ye, Koji Ohta, Mamoru Baba
}

\begin{abstract}
In this paper, we report on effect of thermal annealing on $\mathrm{LiMn}_{2} \mathrm{O}_{4}$ thin films for flexible thin film lithium-ion batteries. The as-deposited film was in amorphous state. When the annealing temperature is over $300{ }^{\circ} \mathrm{C}$, a peak at $2 \theta=18.657^{\circ}$ with $d_{111}=4.75 \AA$ was observed, which suggests that the $\mathrm{LiMn}_{2} \mathrm{O}_{4}$ films were restructured and crystalline spinel films were formed. Increasing the annealing temperature, the full width at half maximum (FWHM) of the (111) peak was decreased, which implies that the annealing temperature significantly improves the crystal quality of the films. While the annealing temperature is over $500{ }^{\circ} \mathrm{C}$, some small impurity phases such as $\mathrm{Mn}_{2} \mathrm{O}_{3}$ were observed. The film with the single-phase spinel structure could be gained at the optimized annealing temperature of $400{ }^{\circ} \mathrm{C}$. On the other hand, increasing the annealing temperature, the discharge capacity of the cathode film is increased. At the annealing temperature of $400{ }^{\circ} \mathrm{C}$, the maximum discharge capacity is $22.75 \mu \mathrm{Ah} / \mathrm{cm}^{2}$, which is twice larger than that of the battery with as-deposited cathode film. Unfortunately, the coulombic efficiency is lower than that of the device for the as-deposited cathode film after the first cycle, which is due to higher internal resistance. Thus, it is necessary to further improve the annealing process for fabrication of flexible thin film battery.
\end{abstract}

Index Terms-Thin film, Sputtering technique, Cathode material, Annealing, Thin film battery

\section{INTRODUCTION}

Thin film lithium or lithium-ion batteries have received a lot of attention due to their potential applications as backup power source in smart cards, battery-assisted RFID tags, wireless sensor networks, real-time clock back-up batteries, and multiple healthcare applications, including hearing aids, automated insulin pumps and wearable health monitoring systems [1]. High quality thin film cathodes with high electrochemical performance are one of the key parts for these batteries. The cathode thin films could be prepared by different methods, including pulsed laser deposition, chemical vapor deposition, sol-gel spin coating, as well as RF magnetron sputtering [2]. However, almost all of the film electrodes need post-annealing at high temperature before they are used as cathodes in the thin film batteries. Since those preparation techniques such as RF sputtering technique normally make amorphous cathode thin film at low temperatures, a post-annealing process is then required for as-prepared film to form a crystallized structure. On the other hand, it has been known that stain steel 304 (SUS304) has a

Rongbin Ye, Koji Ohta and Mamoru Baba: Faculty of Science \& Engineering, Iwate University, Morioka 0208551, Japan, Phone No. $+81-19-621-6364$ series of outstanding properties such as corrosion resistance, oxidation resistance, heat treatment, and formability, which applies high-temperature annealing process. In this work, we report on the fabrication and characterization of RF-sputtered $\mathrm{LiMn}_{2} \mathrm{O}_{4}$ thin films annealed at various temperatures for flexible thin film lithium-ion batteries.

\section{EXPERIMENTAL DETAILS}

$\mathrm{LiMn}_{2} \mathrm{O}_{4}$ thin films of ca. $300 \mathrm{~nm}$ were prepared on $30 \mu \mathrm{m}$ SUS304 substrates using an RF magnetron sputtering equipment (ISP-400, ULVAC), with a typical RF power of $100 \mathrm{~W}$ and an Ar-gas pressure of $1 \mathrm{~Pa}$. After deposition, the samples were thermally annealed at $300{ }^{\circ} \mathrm{C}$ to $600{ }^{\circ} \mathrm{C}$ in a muffle furnace (FO810, Yamato) for $15 \mathrm{~min}$. The crystalline quality and surface morphology of $\mathrm{LiMn}_{2} \mathrm{O}_{4}$ films were studied by X-ray diffraction (XRD) (Rint2200 V, Rigaku) with graphite monochromatized $\mathrm{CuK} \alpha$ radiation and atomic force microscopy (AFM) (Nanocute, SII), respectively.

For fabrication of thin film battery, a solid electrolyte $\mathrm{Li}_{3} \mathrm{PO}_{4-\mathrm{x}} \mathrm{N}_{\mathrm{x}}$ (LiPON) thin film of about $800 \mathrm{~nm}$ was deposited with a typical RF power of $100 \mathrm{~W}$ and in nitrogen gas atmosphere of $1 \mathrm{~Pa}$, and an $\mathrm{Nb}_{2} \mathrm{O}_{5}$ film of $400 \mathrm{~nm}$ as a negative electrode was deposited with a typical RF power of $100 \mathrm{~W}$ and in a mixture gas $(9: 1)$ of $\mathrm{Ar}$ and $\mathrm{O}_{2}$ of $1 \mathrm{~Pa}$ in the ISP-400. All Ti thin films of $250 \mathrm{~nm}$ as current collectors were deposited in a RF sputtering apparatus (SPF210H, Anelva). The RF power was $100 \mathrm{~W}$ and the film growth was performed in an Ar atmosphere of $1 \mathrm{~Pa}$. The constant current (CC) charge-discharge measurements of thin film batteries were performed using source/meters (Keithley 2400) controlled by a computer and Labview and the applied currents were in the range of $5 \mu \mathrm{A} / \mathrm{cm}^{2}$ in the voltage window of 3.2 0.5 V. Complex impedances spectra of thin film batteries were measured by using a frequency response analyzer (Solatron, 1252A) in conjunction with a potentiostat (Solatron, SI 1287) and applying an AC voltage of $10 \mathrm{mV}$ amplitude over the frequency ranging from $0.1 \mathrm{~Hz}$ to 100 $\mathrm{kHz}$.

\section{Results AND Discussion}

Figure 1 shows the XRD patterns of $\mathrm{LiMn}_{2} \mathrm{O}_{4}$ thin films annealed at various temperatures. The as-deposited film was in amorphous state. Peaks marked with * correspond to the SUS304 substrate. When the annealing temperature is over $300{ }^{\circ} \mathrm{C}$, a peak at $2 \theta=18.657^{\circ}$ with $\mathrm{d} 111=4.75 \AA$ was observed, which suggests that the $\mathrm{LiMn}_{2} \mathrm{O}_{4}$ thin films were restructured and crystalline spinel films were formed [3]. Increasing the annealing temperature, the full width at half 
maximum (FWHM) of the (111) peak was decreased as shown in Fig. 2, which implies that the annealing temperature significantly improves the crystal quality of the films. While the annealing temperature is over $500{ }^{\circ} \mathrm{C}$, some small impurity phases $\left(\Delta\right.$, shown in Fig. 1) such as $\mathrm{Mn}_{2} \mathrm{O}_{3}$ were observed although the FWHM was decreased with the increasing of annealing temperature [3]. On the other hand, the smallest $d_{111}$ $=4.74 \AA$ was gained at the annealing temperature of $400{ }^{\circ} \mathrm{C}$. Thus, the film with the single-phase spinel structure could be gained at the optimized annealing temperature of $400^{\circ} \mathrm{C}$.

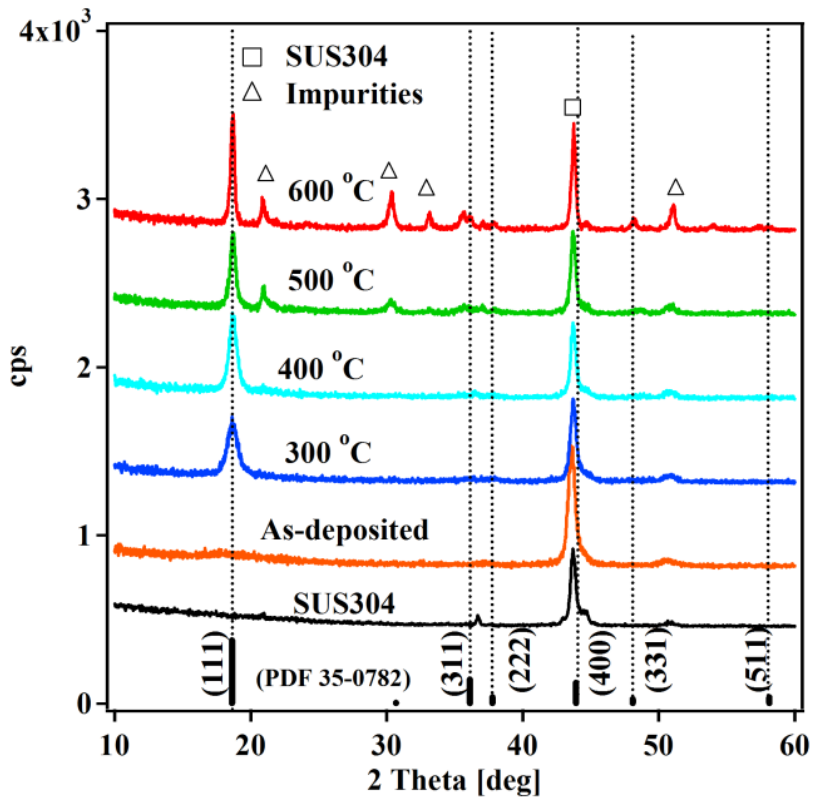

Figure 1 XRD patterns of $\mathrm{LiMn}_{2} \mathrm{O}_{4}$ thin films annealed at various temperatures.

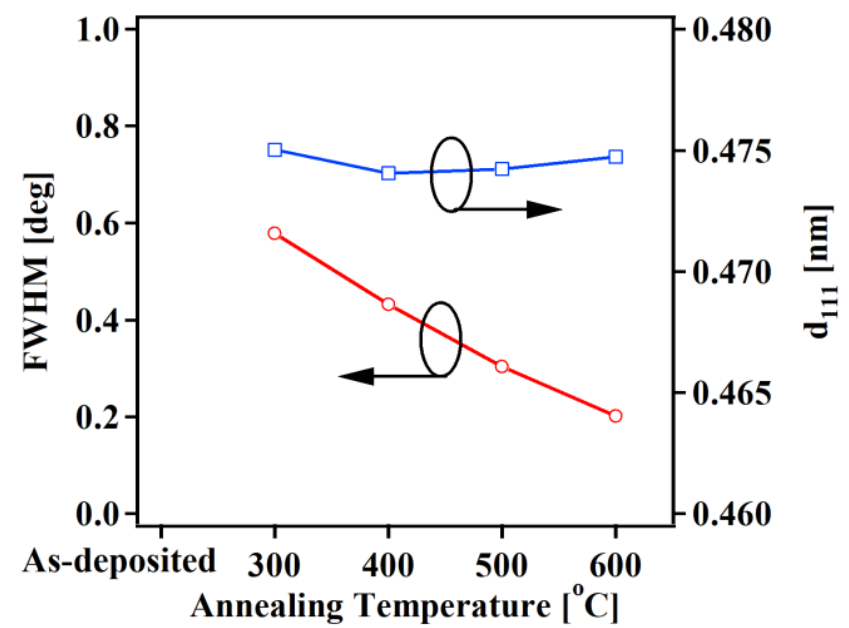

Figure 2 Dependence of $d_{111}$ and FWHM of (111) peak of $\mathrm{LiMn}_{2} \mathrm{O}_{4}$ thin films on annealing temperature.

Figure 3 shows the $5 \mu \mathrm{m} \times 5 \mu \mathrm{m}$ AFM topographic images of $\mathrm{LiMn}_{2} \mathrm{O}_{4}$ thin films annealed at various annealing temperatures. The as-deposited film does not show clear surface structure, and the amorphous nature seen in the image indicates a low degree of crystallinity. With increasing annealing temperature, the morphological changes show a noticeable increase in grain size. The film annealed at $500{ }^{\circ} \mathrm{C}$ shows more growth and more regular particles compared to the films that are as-deposited and annealed at $300{ }^{\circ} \mathrm{C}$; the particles are found to have an average diameter of around 250 $\mathrm{nm}$ at the annealing temperature of $500{ }^{\circ} \mathrm{C}$. We observe that the grain sizes are increased with increased annealing temperature, as nucleation is promoted at lower temperature and suppressed at higher. As the annealing temperature increases, the lattice of the deposited films expands and the volume increases, owing to strain in the film [4]. The result agreed with the above-mentioned XRD analysis.
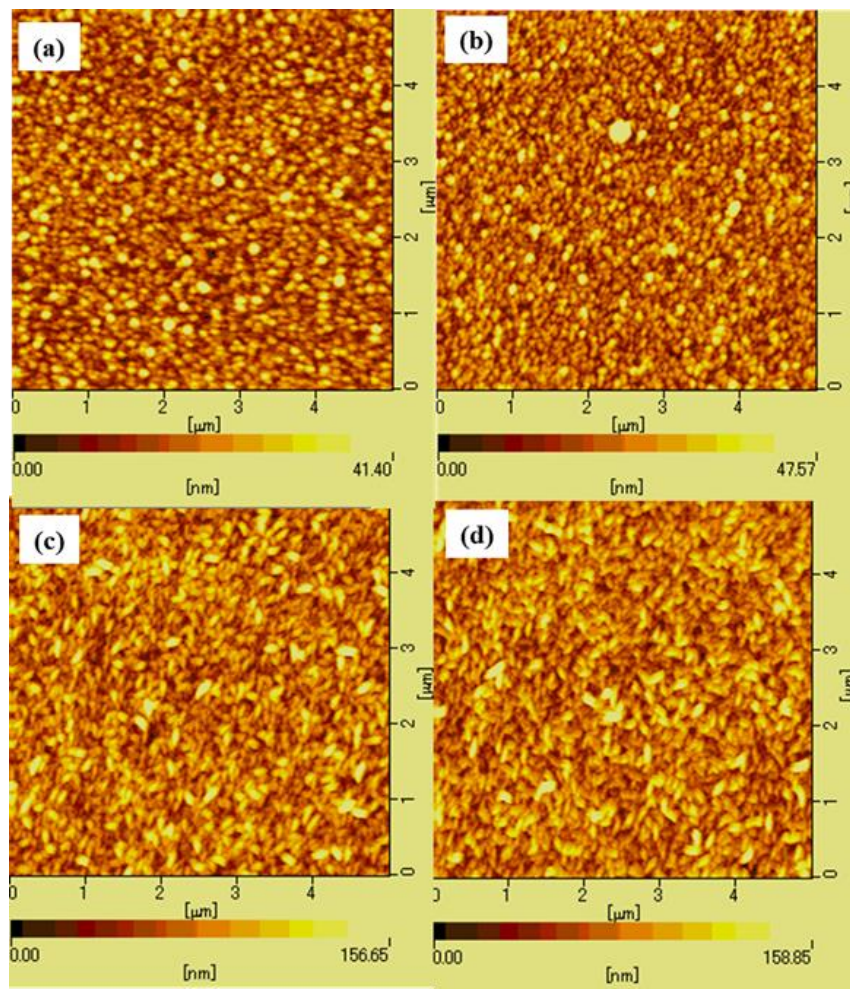

Figure 3 AFM topographic images of $\mathrm{LiMn}_{2} \mathrm{O}_{4}$ thin films annealed at various temperatures: (a) as-deposited, (b) 300 ${ }^{\circ} \mathrm{C}$, (c) $400{ }^{\circ} \mathrm{C}$ and (d) $500{ }^{\circ} \mathrm{C}$, respectively.

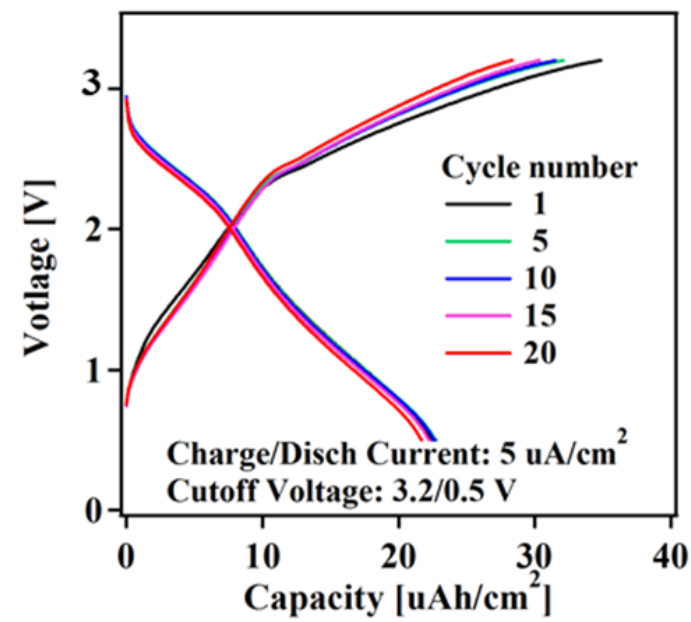

Figure 4 Charge-discharge curves of a thin film battery with the cathode film annealed at $400{ }^{\circ} \mathrm{C}$.

Figure 4 shows charge-discharge curves of a thin film battery with the cathode film annealed at $400{ }^{\circ} \mathrm{C}$, measured at CC mode. The initial discharge capacity is about 22.5 $\mu \mathrm{Ah} / \mathrm{cm}^{2}$. At the 5 7th cycle, the maximum discharge capacity of $22.75 \mu \mathrm{Ah} / \mathrm{cm}^{2}$ is obtained. While over the 14 th cycle, the discharge capacity is gradually decreased to 21.67 $\mu \mathrm{Ah} / \mathrm{cm}^{2}$ at the 20 th cycle. Fig. 5 shows cycle performance of 
thin film batteries with the cathode films annealed at various temperatures. Increasing the annealing temperature, the discharge capacity is increased. At the annealing temperature of $400{ }^{\circ} \mathrm{C}$, the average discharge capacity is about 22.40 $\mu \mathrm{Ah} / \mathrm{cm}^{2}$, which is about twice larger than that of the battery with as-deposited cathode films [5-7]. While the annealing temperature is over $500{ }^{\circ} \mathrm{C}$, the average discharge capacity is decreased, which is due to higher internal resistance.

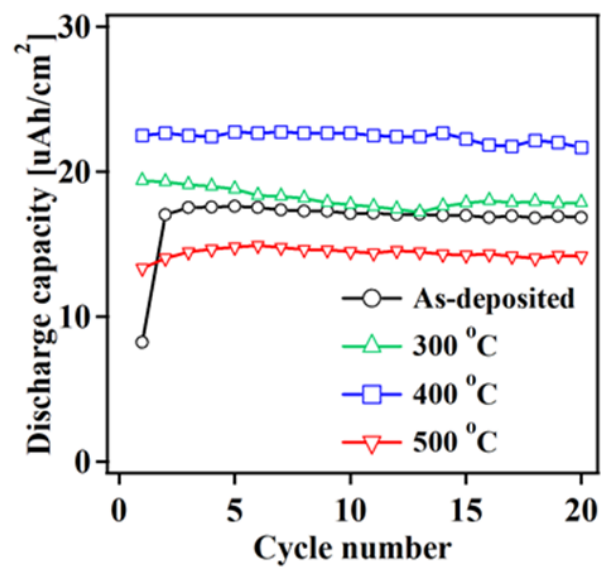

Figure 5 Cycle performance of thin film batteries with the cathode films annealed at various temperatures.

As shown in the Fig. 6a, the lower coulombic efficiency $(29.0 \%)$ at the 1 st cycle for the as-deposited cathode was gained, which is due to higher internal resistance $\left(R_{1}=18000\right.$ ohm), as shown in Fig 6b. When cycle number is over 4, the coulombic efficiency reaches to about $100 \%$, and the value of $\mathrm{R}_{1}$ was quickly decreased to $1700 \mathrm{ohm}$, as shown in Fig 6c. On the other hand, the internal resistance for the annealed cathode was slightly decreased from 5,800 ohm to $3200 \mathrm{ohm}$. Although the cycle number increases, the coulombic efficiency was improved, then is lower than that of the as-deposited cathode device. The increment of the internal resistance was associated with the difficult absorption reaction of the electrolyte and the cathode film, which was oxidized or hardened in the thermal annealing process $[7,8]$. Thus, it is necessary to further improve the annealing process for fabrication of flexible thin film battery.

\section{CONCLUSION}

In this paper, we report on effect of thermal annealing on $\mathrm{LiMn}_{2} \mathrm{O}_{4}$ thin films for flexible thin film lithium-ion batteries. The as-deposited film was in amorphous state. When the annealing temperature is over $300^{\circ} \mathrm{C}$, a peak at $2 \theta=18.657^{\circ}$ with $\mathrm{d}_{111}=4.75 \AA$ was observed, which suggests that the $\mathrm{LiMn}_{2} \mathrm{O}_{4}$ films were restructured and crystalline spinel films were formed. Increasing the annealing temperature, the FWHM of the (111) peak was decreased, which implies that the annealing temperature significantly improves the crystal quality of the films. While the annealing temperature is over $500{ }^{\circ} \mathrm{C}$, some small impurity phases such as $\mathrm{Mn}_{2} \mathrm{O}_{3}$ were observed. The film with the single-phase spinel structure could be gained at the optimized annealing temperature of $400{ }^{\circ} \mathrm{C}$. On the other hand, increasing the annealing temperature, the discharge capacity of the cathode film is increased. At the annealing temperature of $400{ }^{\circ} \mathrm{C}$, the maximum discharge capacity is $22.75 \mu \mathrm{Ah} / \mathrm{cm}^{2}$, which is twice larger than that of the battery with as-deposited cathode film. Unfortunately, the coulombic efficiency is lower than that of the device for the as-deposited cathode film after the first cycle, which is due to higher internal resistance. Thus, it is necessary to further improve the annealing process for fabrication of flexible thin film battery.
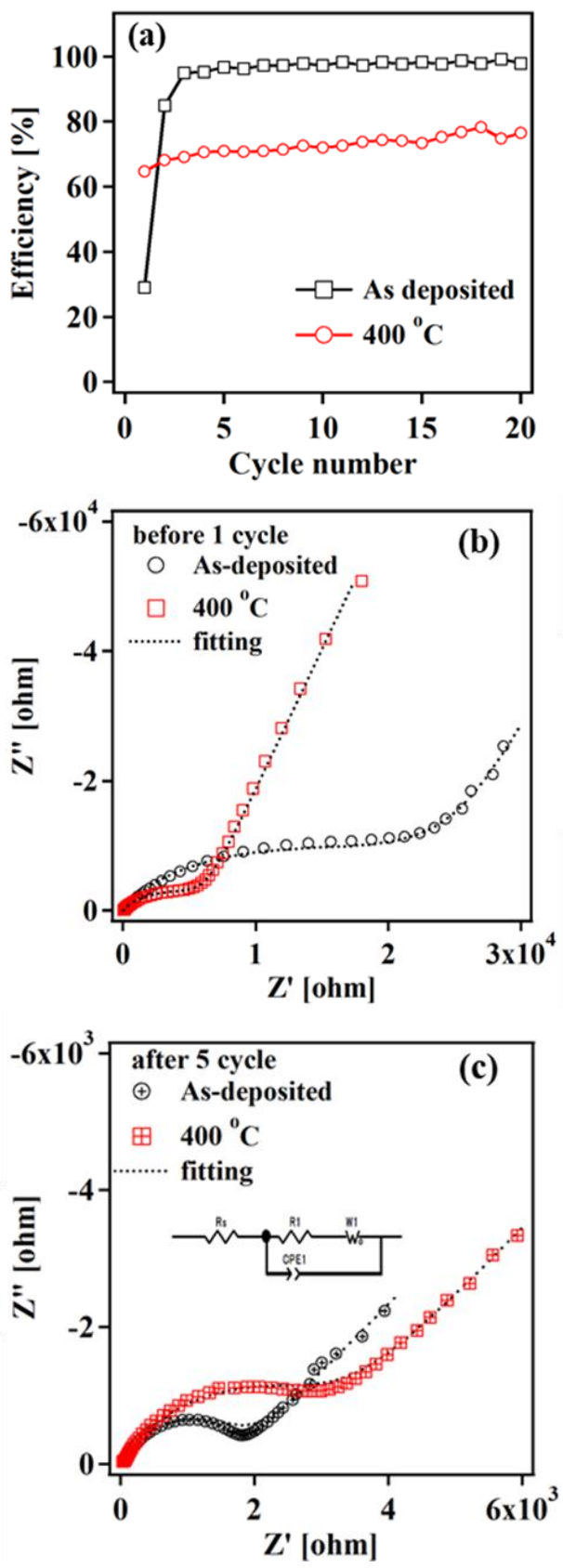

Figure 6 (a) Coulombic efficiency, (b) and (c) Complex impedance spectra of thin film batteries with the as-deposited cathode film and the cathode film annealed at $400{ }^{\circ} \mathrm{C}$. Inset in Fig. $6 \mathrm{c}$ shows circuit elements used for the modeled fitting.

\section{REFERENCES}

[1] S. Priya and D. J. Inman, Energy Harvesting Technologies: Thin Film Batteries for Energy Harvesting, p. 355, Springer, New York (2009).

[2] K. Ozawa, Lithium Ion Rechargeable Batteries Materials, Technologies, and New Applications: Thin-Film Metal-Oxide 
Fabrication and characterization of $\mathrm{LiMn}_{2} \mathrm{O}_{4}$ thin films for flexible thin film lithium-ion batteries: effect of thermal annealing

Electrodes for Lithium Microbatteries, p 257, WILEY-VCH, Weinheim (2009).

[3] H. Xu, S. Xu, H. Wang and H. Yan: J. Electrochem. Soc., 152, C803 (2005).

[4] S. Surampudi, Electrochem. Soc. Proc. 280, 98 (1999).

[5] R. Ye, K. Yoshida, K. Ohta and M. Baba:Adv. Mater. Research, 788, 685 (2013).

[6] N. Nakazawa, K. Sano, T. Abe, M. Baba and N. Kumagai: J. Power Sources, 174, 838 (2007).

[7] R. Ye, Y. Yamani, K. Ohta and M. Baba: ECS Transactions, 59, 79 (2014).
[8] Y. J. Parka, J. G. Kima, M. K. Kima, H. T. Chungb and H. G. Kima: Solid State Ionics, 130, 203(2000).

Rongbin Ye was born in Anhui, China. He received the B. Sc. degree in solid-state electronics from East China Normal University, Shanghai, China, in 1989. He received the M.E. and PhD degrees from Nanjing University of Aeronautics and Astronautics, Iwate University in 1995, and 1999 respectively. His research interest is in thin film devices, organic electronics, and energy harvesting. He is currently working as an associate professor at Iwate University in Morioka, Japan. 